\title{
THE MALPIGHIAN VESSELS OF HALTICA BIMARGINATA SAY (COLEOPTERA).
}

\author{
By William Colcord Woods.*
}

1. The general structure of the larval vessels.

2. The general structure of the vessels of the imago.

3. A comparison of the conditions in Haltica bimarginata with those described for certain other Coleoptera.

4. The function of that portion of the tubes associated with the wall of the colon.

1. THE GENERAL STRUCTURE OF THE LARVAL VESSELS.

INTRODUCTION.

In connection with a study of the internal metamorphosis of the alder flea beetle, Haltica bimarginata Say (Chrysomelidæ), a problem which has been occupying the attention of the writer for some months past, observations have been made on the number and arrangement of the Malpighian vessels in these insects. Some striking features were brought out, which seemed worthy of special mention.

THE ALIMENTARY CANAL OF THE LARVA.

In the alimentary canal of the larva of the alder flea beetle, the three primary divisions, fore-intestine, mid-intestine, and hind-intestine can be made out readily. The fore-intestine consists of a short pharynx, a short oesophagus, and a short, thin-walled distensible crop. The mid-intestine, which forms by far the greater part of the canal, is divided into two regions, separated exteriorly by a constriction, each region having a distinct type of epithelium peculiar to it. The hind-intestine consists of three short regions, a small intestine or ileum, a large intestine or colon, and a very muscular rectum. The distinction between these parts is clear as well in dissected specimens as in sectioned material.

Figure 1, a diagram of the alimentary canal, shows the relationship of these parts, although the intestine is actually more convoluted and the folds overlie one another to a greater extent than is there indicated.

*Contribution from the Entomological Laboratory of Cornell University. 
THE MALPIGHIAN VESSELS.

From a morphological point of view, the Malpighian vessels of an insect are ectodermal structures, which arise during embryonic life as evaginations of the distal end of the hindintestine (which is itself an invagination of the ectoderm). In a typical insect, the Malpighian vessels empty into the alimentary canal at the junction of the mid-intestine with the hind-intestine, and after a greater or less course end blindly in the body cavity.

In the larva of Haltica bimarginata the arrangement is very characteristic and presents some interesting and rather unusual features. In this insect there are six Malpighian vessels, which are morphologically divisible into two series, differing from one another in point of origin, in length, in macroscopic aspect, and in microscopic structure.

Such a dimorphism in the tubes of the same individual is by no means confined to Haltica, but has already been reported for numerous Coleoptera. Indeed, much greater dimorphisrn has been described for many insects, and while most of the instances cited have been discredited by later workers, it is generally admitted that there is a very decided dimorphism, correlated with a difference in function, in the Malpighian vessels of Stratiomyia (Vaney, 1900) and of phasmids (Sinety, 1900).

In Haltica, the first series is composed of four vessels which unite at their bases, forming what is generally termed, from analogy with the vertebrates, an urinary bladder. This small ovoid bladder empties directly into the hind intestine, shortly behind its union with the mesenteron. (This condition is illustrated in Figures 1 and 5). At the point of junction of the mid-intestine and the hind-intestine there is a sharp bend, and between the mesenteron which runs caudad and the ileum which extends cephalad, is formed a strong angle, on the inner side of which the bladder opens directly into the lumen of the intestine.

The four vessels leave this bladder in a parallel series so that there are two outer vessels and two inner. These tubes, which are more or less imbedded in the adipose tissue, are long and somewhat twisted, so that it is difficult to trace their course, especially as they are easily broken. They are closely 
apposed to the alimentary canal throughout most of their extent, but are always entirely distinct from its walls (except in the colon at their distal ends, as will be explained later). Following very closely the course of the mid-intestine and appressed to its walls, they extend forward as far as the beginning of the crop (i. e., into the mesothorax). Here they bend back on themselves and extend nearly to the posterior end of the body. In a typical cross-section through the meso- or metathorax and the first five abdominal segments, therefore, the mid-intestine is surrounded by eight sections of the Malpighian vessels quite regularly arranged, so that one would naturally interpret them as eight distinct vessels if he did not know the true circumstances of the case. At the constriction between the two parts of the mid-intestine, the Malpighian vessels cease to be associated with the walls of the alimentary canal, and then run posteriorly in the fat body as far as the eighth abdominal segment, where they again double back on themselves, and run cephalad to the sixth abdominal segment. Here they pass into the walls of the colon in a manner that will presently be described.

There is a great deal of variation in the length and course of these tubes, and the condition described above is to be regarded as the average condition rather than an exact description of the distribution of the tubes as found in any one individual specimen. Sometimes the vessels are much convoluted, at other times they seem to be nearly straight; in some cases they follow closely the windings of the second division of the mid-intestine in their course cephalad, and at other times they do not; often they do not quite reach the anterior end of the mesenteron and rarely they may even extend a little beyond into the prothorax. But the diameter of the vessels and their color, a dull opaque white, are constant characters in this series.

The second series of vessels arises independently of the first, and some little distance in front. It consists of two isolated Malpighian vessels which enter the alimentary canal at the exact point where the mid-intestinal epithelium ends. Sections through the evagination of these tubes show typical midintestinal epithelium, but the sections immediately succeeding show the beginning of the hind-intestinal epithelium. These 
two vessels leave the intestine side by side, and very close together, but are entirely independent of one another. It should not be inferred from any of the above statements that the writer regards the second series of tubes as appendages of the mid-intestine. The epithelium of that portion of the ileum into which both series of vesse..s empty is strikingly different from that of the remainder of this division of the intestine, and the cells of the Malpighian vessels are very different from those of the mid-intestine. The second series of vessels, as well as the first, belongs to the hind-intestine.

The two vessels which constitute the second series are very much shorter than the four tubes of the first series. They extend only a short distance anteriorly, usually following the twisting of the mesenteron, and then run more or less directly to the junction of the ileum and colon. Under the binocular these vessels appear more delicate than, those of the first series, the diameter is slightly less, the cells are slightly smaller, and in color they are more or less a translucent white, instead of being opaque.

Thus far we have traced the course of the four vessels of the first series and the two vessels of the second series, and have seen that all six finally extend to the vicinity of the strong bend caudad in the alimentary canal, which marks externally the end of the ileum and the beginning of the colon.

The four vessels of the first series, which represent two pairs, at the distal ends of their coelomic portions unite into two common stems, consisting of two vessels each. One of the short vessels of the second series soon becomes closely associated with each stem, and thus all six of the tubes have now been accounted for. Each stem with its apposed vessel applies itself closely to the wall of the colon, one on the dorsal side and one on the ventral. Up to this point the vessels of the second series remain distinct, but here each fuses with the stem with which it is associated, and thus two common trunks, representing three vessels each, are formed, one lying on the dorsal wall of the colon and one on the ventral wall.

In Haltica bimarginata the colon consists of the following parts $_{2}$ passing toward the exterior: intima, epithelium, basement membrane, circular muscle layer, longitudinal muscle layer, (and later a layer of Malpighian vessels and a peritoneal 
layer). All of the intestinal muscles, both circular and longitudinal, are clearly striated. The circular muscles are strongly developed in all but the posterior portion of the colon; there is a single row of them forming a continuous layer around the alimentary canal. The longitudinal muscle. layer consists of six large fibres, which are rather regularly disposed, outside of the circular muscles.

Each vessel trunk lies between two of these longitudinal muscle fibres. As soon as the vessels have become appressed to the wall of the colon, their peritoneal sheaths grow out and join, so that a continuous peritoneal coat is formed, completely surrounding the colon, and enclosing the six muscle fibres and the two Malpighian trunks. As soon as this tunic is complete, each of the trunks redivides into three vessels, which almost immediately begin to "migrate" outside the muscle fibres so as to lie alternately with them. This "slipping" or "migration" extends through about twenty sections of six micra each before it is completed. The condition which results characterizes the greater part of the colon and in a typical cross section, one will find lying without the circular muscles, a layer composed of the six longitudinal muscle fibres alternating with the six Malpighian vessels, the whole surrounded by a nucleated peritoneum, probably of connective tissue, which, as it represents the investing sheath of the vessels, is a double layer. The two sheets separate at the vessels, one layer passing inside and the other outside of the tubes, but both sheets pass outside of the longitudinal muscles.

Figure 2 shows the Malpighian vessels after they have separated from the trunk "migrating" outside the fibres of the longitudinal muscles. Figure 3 shows diagrammatically a typical cross section of the colon. In reality the epithelium is not a syncytium.

In the more anterior part of the colon, the cross sections of the Malpighian vessels and of the longitudinal muscles are about equal in diameter. But as one traces the sections caudad, the Malpighian vessels gradually increase in size while the muscles decrease in size, and two thirds of the way to the end of the colon this has become very marked, the Malpighian vessels here being twice as large as the muscles. At this point the longitudinal muscles begin to diminish in size rapidly 
and become very small, although they persist faintly to the end of the region. The circular muscles also decrease so markedly as to be almost negligible. The Malpighian vessels, which have been almost circular in cross sections, now become elongated along the diameter perpendicular to the axis of the canal, and tend to crowd the longitudinal muscles inside. This tendency becomes more and more pronounced, and some little distance before the end of the colon, the intestine is surrounded by a practically continuous layer of Malpighian tubes, with the small longitudinal muscles intercalated between them. The vessels do not extend along the wall of the rectum, but seem to terminate blindly at the posterior end of the colon.

It is very difficult to make out the exact course of the vessels in the walls of the colon in a dissected specimen. They seem to extend posteriorly as six parallel tubes, at first of slight diameter and almost straight; but, as was noted in the preceding paragraph, as the diameter increases, they become more and more wavy, with larger and larger folds. It is this character which makes the vessels appear so elongated in cross sections. Toward the end of the colon, these undulatory folds are so large that those of one series almost touch those of the adjacent series, and thus they almost completely surround the wall of the colon. The vessels seem to branch irregularly, the tubes terminating blindly and separately in irregular ramifications, just anterior to the strong circular muscles which appear abruptly, and mark externally the beginning of the rectum. The tubes in the wall of the colon have an extremely abundant tracheal supply, a fact which makes dissection difficult, and makes it much harder to trace them out.

The distribution and ramification of one of the Malpighian trunks in the wall of the colon is shown diagrammatically in Figure 4. It should be noted that the strong circular muscles which mark the beginning of the rectum are peculiar to that region, and there are no muscles overlying the Malpighian vessels in the wall of the colon.

We may summarize, then, the distribution of the Malpighian tubes in the larva of Haltica bimarginata as follows, beginning at their distal ends. Six Malpighian vessels extend parallel to one another, running cephalad in the wall of the colon. They unite at the anterior end of this region to form two common trunks, which leaving the wall of the intestine, split up 
into a single tube and a common stem representing a pair of tubes. The single tube, which is very short and delicate, runs quite directly to the mesenteron, where it is inserted isolated into the wall of the intestine, just at the point of junction between the mid-intestine and the hind-intestine. Each common stem soon splits up into two vessels which have a long course through the body cavity. Eventually the four vessels unite to form a single common urinary bladder, which empties into the hindintestine at a point a little posterior to the insertion of the two shorter tubes. This condition is shown very diagrammatically in Figure 5.

\section{THE GENERAL STRUCTURE OF THE VESSELS OF THE IMAGO.}

The Malpighian vessels of the adult beetle of Haltica bimarginata have exactly the same relations as have just been described for the larva.

\section{A COMPARISON OF THE CONDITIONS IN Haltica bimarginata} WITH THOSE DESCRIBED FOR CERTAIN OTHER COLEOPTERA.

Not one of the general features noted above, although very different in many respects from the typical arrangement in insects, is peculiar to Haltica bimarginata, but all of these relations have been described for other forms, although so far as the writer is aware, there has never been a single species of insect recorded in which so many of them were illustrated.

It has long been known that the Malpighian vessels may have two apparent terminations in the intestine. In all known. cases the second termination is merely superficial, in the walls of either the colon or the rectum, and the vessels do not empty into the alimentary canal except at the point of their evagination.

So far as the writer has been able to ascertain, the earliest work in which there is any reference to such a condition is Ramdohr's paper, which appeared in 1811. He figured the alimentary canals of at least 22 genera of Coleoptera, representing 10 families, 2 genera of Neuroptera, 3 genera of Hemiptera, 1 genus of Lepidoptera, and 1 genus of Diptera, in which the Malpighian vessels become reassociated with the alimentary canal at their distal ends, although he did not discuss this point at length. 
The next reference is to be found in the classic work of Straus-Durckheim on a scarabaeid, Melolontha vulgaris, which was published in 1828 .

Léon Dufour seems to have been the first man who did extended work on the Malpighian vessels of insects, and was the first author to point out the fact that the posterior intestinal insertion of the Malpighian vessels is only superficial. In discussing the metamorphosis of Mordelia fasciata (Coleoptera) he wrote in 1840: "* * * I have always thought that this insertion penetrated the tunics of the coecum or the rectum in such a manner that the vessels might discharge a portion of their products of secretion into the interior of the latter. It is thus that all entomotomists have regarded this point of anatomy. $* * *$ The posterior or coecal insertion of the hepatic vessels of the larva of Mordella (and perhaps or probably of all insects) is only superficial. These vessels instead of emptying into the intestine $* * *$ simply ramify and are lost in a hyaline membraniform tissue which surrounds it. * * *" (Pages 231 and 232).

Dufour published a memoir on the Malpighian vessels in 1843, in which he discussed this double insertion still further, and described the conditions as he found them in several chrysomelids. In speaking of Donacia, he said in part: “* * * These vessels, which lack a rectal insertion, differ between themselves in size and the manner of insertion; they have * * * only a ventricular insertion, and although they appear to be six in number, there are really but four vessels. Two, much thinner and handle-like (à anses) are inserted by their four ends into an ovoid sessile body, which is a sort of gall-bladder (vésicule biliaire); two others, shorter, larger, swollen, large-bellied (ventrus) in the middle and floating at one end, are implanted isolated at the extremity of the ventriculus on its superior face." (Page 156). In Crioceris merdigera, "* * * the rectal insertion takes place by two trunks of two branches, and by two isolated vessels; and the ventricular, first by a lateral gall bladder as in Donacia, which receives four vessels, and then by two other more delicate vessels, colorless and isolated." (Page 157). "In Cassida the four principal vessels are grouped, but not confluent for their ventricular insertion; this takes place in the ventral wall of 
that organ; the thinner vessels are separately inserted. The fixation at the rectum is made by two trunks of three vessels as in the longicorns." (Page 157). "Galeruca tanaceti * * * have the four principal vessels inserted on the ventriculus by a single very short stump (souche) which does not deserve to be called a gall bladder, and fixed on the rectum by two well distinct trunks. The thin walled vessels have isolated insertions." (Page 158). On the same page the conditions are described for $G$. lusitanica, the only difference being that here the ventricular insertion of the four tubes of the first series is not by a bladder, but separately.

In a general way the conditions in Haltica agree with those described by Dufour. His generalization (page 154) that in tetramerous Coleoptera the posterior insertion is never unicauline (by one trunk) as in the great majority of the heteromerous, but is bicauline (by two trunks) or fasciculated, holds true for bimarginata, in which the bicauline condition exists. In Crioceris, in Cassida, and in Galeruca there are two series of vessels, a series of four large tubes, and a series of two smaller more delicate vessels, just as is the case in the alder flea beetle. In Donacia also, the two series of tubes can be recognized. In most cases the four vessels of the first series empty through a bladder (an urinary bladder of course and not a gall bladder) and there is a colonic insertion of the tubes as occurs in Haltica bimarginata. (Although Dufour always speaks of a rectal insertion of the vessels, he used this term loosely; and in reality all of his figures show the Malpighian vessels passing very clearly into the wall of the colon, or second division of the hind intestine, and not into the rectum, or third division.) In nearly every case which he figured, the vessels of the second series are isolated in their ventricular insertion.

The greatest differences appear when Haltica bimarginata is compared with Donacia. In both cases there are two series of vessels, the first series comprising four tubes, emptying into the alimentary canal by a common bladder, and the second comprising two shorter vessels with isolated insertions. In the latter insect, the four vessels of the first series unite at their distal ends, and it is for this reason that Dufour regarded them as really only two vessels, and referred to them as handle-like (vaisseaux à anses). The fusion of the vessels into two common 
stems in the alder flea beetle is probably homologous with this fusion into two pairs in Donacia. In Haltica, these vessels enter the colon wall and terminate blindly there, whereas in Donacia, they are fused into two pairs which lie free in the body cavity throughout their extent, and they have no free distal ending.

The vessels of the second series also present a very marked. contrast in the two forms, the only point of similarity being that in both species they are shorter than the first series, and have isolated insertions. But whereas they are slender and delicate in Haltica, they are large and swollen in Donacia, much larger than the tubes of the first series, a very unusual condition which has been reported for no other chrysomelid genus. The distal ends of the vessels lie in the wall of the colon Haltica, and free in the body cavity in Donacia.

In Crioceris the conditions are almost identical with the alder flea beetle, in so far as Dufour has described them. In Cassida, the ventricular insertion is very different, but the superficial distal insertion is very suggestive of the condition in $H$. bimarginata.

Although Dufour was the first to state the probability that the posterior insertion of the vessels is merely superficial in all cases, he does not appear to have been fully convinced that this was true, especially in Myrmeleon formicarium. It remained for Sirodot in 1858, who summarized the results of earlier workers in a very satisfactory way, to demonstrate that in all cases, not excepting Myrmeleon, the posterior insertion is absolutely superficial, the vessels simply ramifying in the wall of the canal. His final statement in regard to the matter was: "As a general conclusion, then, the extremities of the Malpighian tubes are either free or united in bundles, but always without any alteration of the independence of their lumen." (Page 261).

Schindler's paper in 1878 was the next important contribution to our knowledge of the Malpighian vessels. Summarizing the results of his own studies on Coleoptera and those of preceding writers, he said: "Where one finds six vessels, it is often the case that they unite with one another at their extremities into one or two apparently common stalks, and seem to empty into the rectum, which is however, never the case, for after the common stalk has penetrated the outer layer of the 
canal, the vessels again separate and bury themselves, ending blindly beneath this coat." (Page 630).

Schindler also recorded the condition of the vessels in Haltica nemorum. "Léon Dufour has already pointed out that in Donacia two pairs of winding 'gall-vessels' empty into a single 'gall-bladder' on the side of the stomach, while two other isolated canals are inserted in the under part of the stomach. A very similar condition is demonstrable in Haltica nemorum. Here the first four urinary tubes-in this case blind-endedempty into a pyriform bladder. The bladder, which is only a urinary bladder and not a gall bladder, measures $1.0 \mathrm{~mm}$. in cross section, and empties through a stalk (Stiel), the urethra, almost $1.5 \mathrm{~mm}$. long, into the upper end of the large intestine (Mastdarm). * * * Shortly above this insertion two more urinary tubes empty isolated into the pylorus." (Page 631).

While this account agrees in a general way with the condition of the tubes in Haltica bimarginata, it is very surprising to find such great differences in species belonging to the same genus. The bladder of bimarginata is proportionately smaller, and there is no stalk at all. Admittedly this is a minor character; but the fact that the vessels end distally in the wall of the colon in the one species and blindly in the body cavity in the other, is remarkable. Schindler makes no statement in regard to the comparative length of the two series of vessels in nemorum, and as he has evidently used the terms "large intestine" and "pylorus" loosely, it is impossible from his description to make an accurate comparison of the ventricular insertion in the two species.

In 1910 Poyarkoff published an article dealing with the metamorphosis of another chrysomelid, Galerucella luteola, in which he described the larval vessels. According to his statement, they are four in number and empty into the second division of the hind intestine at the end of a comparatively long coecum. (He recognizes four regions in the hind-intestine). These four vessels after a long course through the body pass into the wall of the colon, where two of them bifurcate, so that there are six vessels associated with this portion of the intestine (the third region). (Pages 337, 401-402 and 414).

The condition described above is entirely different from that in Haltica bimarginata, save that in the latter also there are 
six vessels associated with the wall of the colon. However, the distribution of these vessels in the colon wall of Galerucella, according to Poyarkoff, is very similar to the alder flea beetle. In Galerucella they are at first small, and then they become larger, ramifying irregularly so as to form an almost complete layer around the canal. In his figures, the peritoneal envelope is shown passing around the Malpighian vessels and outside the longitudinal muscles, just as has been described above for Haltica bimarginata.

The most recent paper dealing with the general subject of Malpighian tubes is the valuable contribution of Gorka in 1914. He studied two genera of Coleoptera, Gnaptor (family Tenebrionidæ) and Necrophorus (family Silphidæ). In his general summary may be found the following conclusions: "The number of Malpighian vessels is six in Gnaptor spinimanus and four in Necrophorus humator. In Gnaptor the Malpighian vessels build a network on the walls of the rectum, yet without emptying into it. Out of this network, which is due to the union of the vessels in pairs after a long wavy course on the walls of the rectum, a single thick stem is formed. This stem does not represent a fusion of the Malpighian vessels, but only a very close apposition. The common stem then divides into two branches, each of which consists of three vessels. Finally these also separate out and empty after a short course through the body cavity into the intestine, at the boundary of the mid-intestine and the hind-intestine. The Malpighian vessels of Necrophorus end blindly. In all the beetles studied the Malpighian vessels empty into the mid-intestine, and not into the hind-intestine. A few epithelial cells follow behind the insertion of the Malpighian vessels in Gnaptor, which agree with the epithelial cells of the mid-intestine in every respect." (Pages 330 and 331).

Only in a very general way does this recall the condition in Haltica bimarginata. In the latter the vessels do actually fuse, and the two common trunks represent a real coalescence, not simply a close apposition of the tubes. There is no indication that the trunk is composed of three distinct vessels, but in cross sections it appears like an ordinary Malpighian tube, and is not of an appreciably greater diameter. In Cassida, as figured by Dufour (Ann. de. sci. nat. 1825, ser. 1, t. 4, pl. 8, 
fig. 1) one would also infer that there was a fusion of the three vessels and not simply an apposition. However, Gorka states that under high magnification, even without sectioning it can be seen in Gnaptor that the fusion is only apparent and not real.

In $H$. bimarginata there is a bladder and a dimorphism of the vessels correlated with a difference in their insertion and in their length, features no one of which is found in Gnaptor. Finally it is very clear in Ifaltica that the vessels pass into the wall of the colon, while from the figures of Gnaptor it seems equally clear that it is actually the wall of the rectum into which the vessels penetrate. It is evidently the colon into which the Malpighian tubes pass in all of the figures of chrysomelid alimentary canals drawn by Ramdohr (1811) and Dufour (1823-25, 1840, 1843).

Moreover the vessels of the alder flea beetle are very clearly appendages of the hind intestine and not of the mid-intestine. One would need very conclusive embryological data to be convinced that the Malpighian vessels were really appendages of the mid-intestine and not merely associated with it secondarily.

\section{THE FUNCTION OF THAT PORTION OF THE TUBES ASSOCIATED WITH THE WALL OF THE COLON.}

While working on the larvæ of Galleria mellonella (Lepidoptera) in 1908, Metalnikov demonstrated that the cells in the "tubes contournees" (as he termed that portion of the Malpighian vessels associated with the wall of the colon) never pass through the cyclic changes characteristic of the cells of the free portion of the vessels, and indicatory of secretory activity, nor do they take up any coloring agents injected into the body cavity. He formulated the hypothesis that this part of the tubes constitutes a special excretory apparatus which eliminates such toxic substances as may have passed through the intestinal epithelium.

This is the opinion of Poyarkoff (1910) and substantially that of Gorka (1914) who further confirmed the fact that there is a difference in the reactions and function between the portion of the tubes lying free in the body cavity and the portion associated with the hind intestine. 
There seems no reason to doubt that the close association of the Malpighian vessels with the walls of the colon is for the purpose of excreting toxic products just as these authors have already pointed out. In Haltica bimarginata it is probable that most if not all of the digestion and absorption takes place in the mid-intestine. It also seems very likely that on account of the strong continuous layer of circular muscles the liquids absorbed do not at once pass into the body cavity, but flow backward between the basement membrane and the circular muscles. It may well be true that the greater part of this material does not pass outside the circular muscle layer until well along in the colon. Here its passage into the body cavity would be retarded by the peritoneal sheath which completely surrounds this region, and the absorbed liquids would thus be brought into close contact with the distal ends of the Malpighian vessels, which lie closely pressed against the muscle wall of the colon. Here doubtless such poisons and other harmful substances as the intestinal epithelium has allowed to pass through it are taken up by the cells of the Malpighian vessels and excreted before they have had any chance to pass into the body cavity of the insect.

The writer wishes to acknowledge his indebtedness to Dr. W. A. Riley of this Department, under whose general direction the work was carried on, for numerous suggestions and helpful criticisms. 


\section{LITERATURE CITED.}

Dufour, Leon-1823-1825. Recherches anatomiques sur les Carabiques et sur plusieurs autres insectes Coleoptères. Ann. de sci. nat. ser. 1, t. 2: 462-482; pl, 20-21; ser. 1, t. 3: 215-242 476-491, pl. 10-11, 13-15, 29-31; ser. 1, t. 4: pl. 5-8. 1840. Histoire des métamorphoses et de 1' anatomie des Mordelles. Ann. de sci. nat. ser. 2, t. 14: 225-240, pl. 11.

1842. Historie comparative des métamorphoses et de l'anatomie des Cetonia aurata et Dorcus parallelipipedus. Ann. de sci. nat. ser. 2, t. 18: 162-181, pl. 4-5.

1843. Memoire sur les vaisseaux biliaires ou le foie des insectes. Ann. de sci. nat. ser. 2, t. 19: 145-182, pl. 6-9.

Gorka, Alexander von.-1914. Experimentalle und morphologische Beitràge zur Physiologie der Malpighi'schen Gefasse der Käfer. Zool. Jahrb. Abt. f. Zool. Bd. 34, 233-338, pl. 10-11.

Metalnikov, Sergius Iwan-1908. Recherches expérimentales sur les chenilles de Galleria mellonella. Arch. de zool. exp. et gén. ser. 4, t. 8: 489-588, pl. 17-21, text figs. 1-15.

Poyarkoff, Eraste-1910. Recherches histologiques sur le metamorphose d'un Coleoptere (la galeruque de l'orme). Arch. d'anat. micr. t. 12: 333-474, text figs. 1-69.

Ramdohr, Karl August-1811. Abhandlung uber die Verdauungswerkzeuge der Insekten. Halle, 221 pp., $30 \mathrm{pl}$.

Schindler, Emil-1878. Beitrăge zur Kenntnis der Malpighis'chen Gefässe der Insecten. Zeit. f. w. Zool. Bd. 30: 587-660, p1. 38-40.

Sinety, Robert de-1900. Les tubes de Malpighi chez les Phasmes. Bull. Soc. ent. de France, 1900, p. 333-335.

Sirodot, S. - 1858. Recherches sur les secretions chez les insectes. Ann. de sci. nat. ser. 4, t. 10: 141-189, 251-334, pl. 9-20.

Straus-Durckheim, Hercule-1828. * * * L'anatomje comparee des animaux articules. *** 434 pp., 10 pl., Paris.

Vaney, Clement-1900. Note sur les tubes de Malpighi des larves de Stratiomys Bull. Soc. ent..de France, 1900, p. 360-361. 


\section{EXPLANATION OF PLATE.}

Frgure 1. The alimentary canal of the larva of Hallica bimarginata.

b-urinary bladder.

c--colon.

cr-crop.

i-ileum.

$m_{1}$-first division of the mid-intestine.

$\mathrm{m}_{2}-$ second division of the mid-intestine.

o--oesophagus.

p--pharynx.

r-rectum.

The walls of the alimentary canal are represented by dotted lines. lines.

The course of the four Malpighian vessels of the first series is shown by wavy lines.

The course of the two Malpighian vessels of the secont series is shown by solic!

FIGCRE 2. Diagrammatic cross section of the colon showing the Malpighian vessels migrating around the longitudinal muscles.

i-intima.

e-epithelium.

cm-circular muscle layer.

$1 \mathrm{~m}$-longitudinal muscle fibres.

mv--malpighian vessels associated with the colon.

pe-peritoneal envelope.

FIgURE 3. Diagrammatic cross section of the colon showing the typical alternation of Malpighian vessels and longitudinal muscles.

i-intima.

e-epithelium.

$\mathrm{cm}$-circular muscle layer.

$1 \mathrm{~m}$-longitudinal muscle fibres.

mv-malpighian vessels associated with the colon.

pé-peritoneal envelope.

FIGURE 4. Diagram showing the ramification of one of the Malpighian trunks in the wall of the colon.

C-colon.

$\mathrm{R}-\mathrm{rectum}$.

FIGURE 5. Scheme showing very diagrammatically the insertion and relation of the two series of Malpighian vessels.

C-colon.

I-ileum.

$\mathrm{M}$-mid-intestine.

$\mathrm{R}$-rectum. 


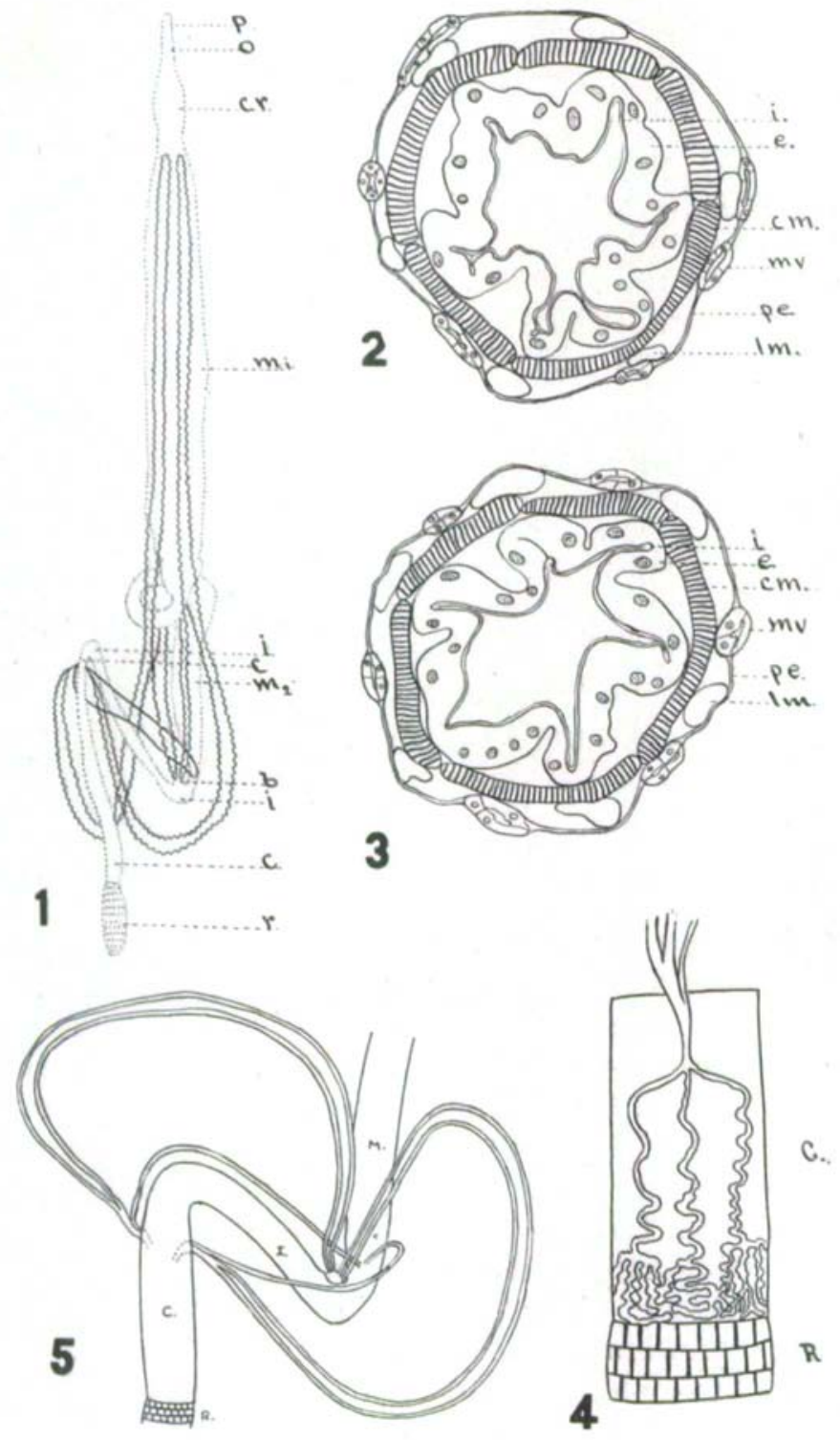

